\title{
Cancer morbidity in ulcerative colitis
}

\author{
P PRIOR, S N GYDE, J C MACARTNEY, H THOMPSON, \\ J A H WATERHOUSE, and $R \mathbf{N}$ ALLAN
}

From the Gastroenterology Unit, General Hospital, Birmingham, and Cancer Epidemiology Research Unit and Department of Pathology, University of Birmingham, Birmingham

SUMmARY Cancer morbidity at all sites has been studied in a series of 676 patients with ulcerative colitis under long-term review, of whom more than two-thirds had extensive disease, and the level and pattern of risk over time examined. Age-, sex-, and site-specific incidence rates were used to compute the number of cancers that might have been expected to occur. A highly significant excess of cancers was observed overall but the excess was due entirely to cancers of the digestive system. In women there was no excess or deficit of cancers outside the digestive system. In men there was a small deficit of cancers of the respiratory system. An overall 11-fold excess colorectal cancer risk was found in the series compared with that in a relevant general population after patient-years at risk had been corrected for surgical resection and patients with colorectal cancer at their first referral had been excluded. When these data were expressed in an actuarial form the cumulative probability of developing colorectal cancer in the series was $8 \%(3 \cdot 5-13 \%)$ at 25 years, after the diagnosis of ulcerative colitis had been established. The relative risk of developing colorectal cancer was highest in those patients developing colitis before the age of 30 years, and the relative risk fell as the age at diagnosis of their colitis increased. The pattern of risk of colorectal cancer over time suggests that there is an association between cancer and colitis in susceptible individuals and that the level of risk is related to age at onset of colitis.

Previous studies of the cancer risk in ulcerative colitis ${ }^{1-8}$ have been confined almost exclusively to colorectal cancer, with the exception of the hepatobiliary system, which has received some attention. ${ }^{-10}$ There is little information about the cancer incidence at other sites. We have therefore studied the whole spectrum of cancer morbidity in a series of patients with ulcerative colitis. This enabled us to examine some aspects of patient selection (analysis of clinical series being subject to many elements of bias $^{3}$ ) to provide a basis from which to approach the specific problem of colorectal cancer.

Estimates of the incidence of colorectal cancer complicating ulcerative colitis in the early literature were based on crude percentages. ${ }^{1}$ Actuarial methods are now used which take into account the decreasing numbers of patients at risk for cancer over extended periods of observation. A number of such studies have been published and are referenced in two recent reports. ${ }^{3}$ Most studies have been interpreted as showing a raised and increasing risk

Received for publication 26 October 1981 of colorectal cancer over time, although only a few $^{24-7}$ have compared the risk in the series with that in a relevant general population. Despite these reports, the magnitude and the pattern of risk is uncertain and varies from one reported series to another. These variations probably reflect differences in the composition of the reported series and in the methods used to evaluate the risk rather than real differences in the underlying cancer risk. The differing approaches to analysis have been discussed ${\text { both in } \text { general }^{3611} \text { and in individual series. }}^{7}$

We have attempted to identify and, where possible, to correct for areas of bias that can arise in analysing data from a clinical series. The increasing incidence of cancer that might be expected to occur in any series under long-term review - that is, an ageing population - has been taken into account when assessing the risk which might otherwise be attributed to the presence of ulcerative colitis. The effects of differing methods of analysis on the pattern of risk of colorectal cancer over time are presented. Finally, the relationship between the risk of colorectal cancer and age at onset of colitis has been examined. 


\section{Methods}

PATIENTS: COMPOSITION OF SERIES

A consecutive clinical series of patients with ulcerative colitis under the care of Professor B N Brooke and $\mathrm{Dr}$ W T Cooke at the Queen Elizabeth and General Hospitals, Birmingham, comprising both primary and referred cases presenting between 1940-76, has been studied. The survivors are under regular review in the Gastroenterology Unit at the General Hospital.

The diagnosis of all patients with inflammatory bowel disease has been reviewed to distinguish patients with ulcerative colitis and Crohn's disease as accurately as possible.

Fifty-nine cases have been excluded from the original series of patients with ulcerative colitis reported by Daly et al. ${ }^{12}$ The reasons for exclusion were polyposis coli (two cases), melanosis coli (one case), Crohn's disease (41 cases), and insufficient information for analysis (15 cases), leaving a series of 676 patients for assessment. For untraced patients $(\mathrm{N}=15)$ the years of survival are truncated if they exceed the appropriate life table estimates.

Of the 676 patients, $142(21 \%)$ have died and the vital status at the end of the review period was unknown for 15 patients $(2 \cdot 2 \%)$. The clinical status was determined in $95.7 \%$ of those known to be alive by clinical examination, report from clinician, or personal communication.

Nearly half the patients were seen in their first attack. The remainder were referred later in the course of their disease. As these 'referred' cases were included, the bias at entry to the series was inclined towards severe disease, particularly as patients were often referred for surgical treatment. This accounts for the high proportion of patients treated by panproctocolectomy (Table 1) compared with other reported series. It was difficult to define

Table 1 Proportion of patients undergoing radical surgery for ulcerative colitis among reported hospital series

\begin{tabular}{llll}
\hline & $\begin{array}{l}\text { Number of } \\
\text { patients in } \\
\text { total series } \\
I\end{array}$ & $\begin{array}{l}\text { Patients } \\
\text { undergoing } \\
\text { radical surgery } \\
\text { II }\end{array}$ & $\begin{array}{l}\text { \% of } \\
\text { total } \\
\text { series } \\
\text { III }\end{array}$ \\
\hline $\begin{array}{l}\text { Nefzger and Acheson } \\
\text { (US Army) } 1963^{13}\end{array}$ & 525 & 40 & \\
$\begin{array}{l}\text { Edwards and Truelove } \\
\text { (Oxford) 1964 }\end{array}$ & 624 & 87 & 8 \\
$\begin{array}{l}\text { Watts et al (Leeds) 1966 } \\
\text { Bonnevie }\end{array}$ & 204 & 56 & 14 \\
$\begin{array}{l}\text { (Copenhagen) 1974 } \\
\text { Present series }\end{array}$ & 332 & 56 & 27 \\
(Birmingham) & 676 & 438 & 17 \\
\hline
\end{tabular}

an accurate date of diagnosis for some of the referred patients. If the date of diagnosis could not be established it was taken as the date first seen at the Queen Elizabeth or General Hospitals.

The age-distribution at onset and diagnosis is shown in Fig. 1. The extent of the disease and the frequency of surgical resection is shown in Table 2. Extensive colitis was defined as involvement of the large intestine as far proximally as the hepatic flexure.

The diagnosis of colorectal cancer was confirmed in all cases by a review of the histopathological material, and an accurate Dukes's classification was made whenever possible.

\section{STATISTICAL ANALYSIS}

Person-years at risk

The date of diagnosis was used as the starting point for computing person-years at risk. The analysis was based on 10665 person-years at risk (PYR), yielding a mean follow-up of 15.8 years per patient (14.2 for men and 16.8 for women). For each patient the length of follow-up was computed from the date of diagnosis to 31 December 1976 or to death if this occurred earlier. The survival experienced by the whole series was expressed as person-years at risk in terms of sex, age, and interval from diagnosis. In

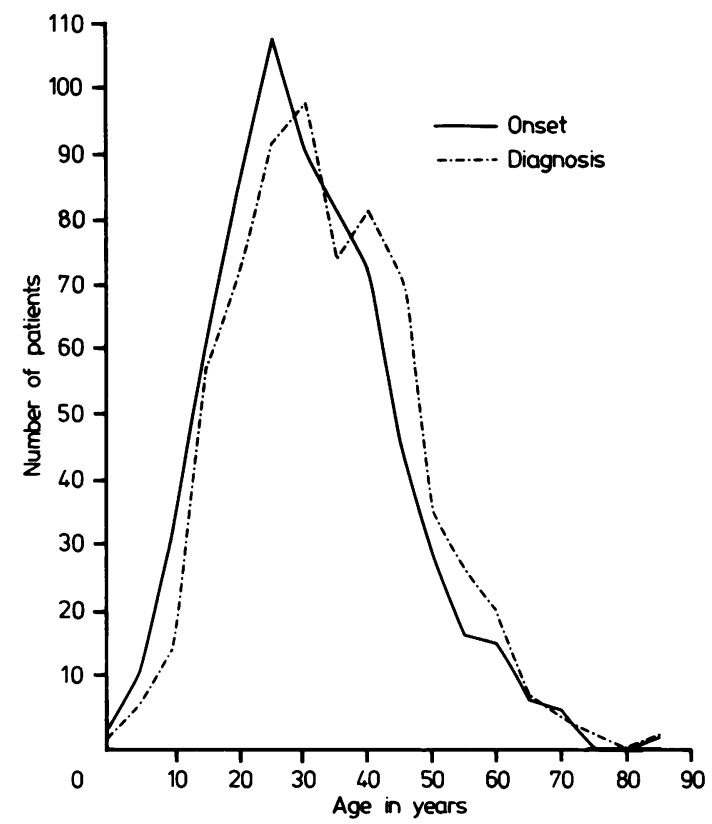

Fig. 1 Age distribution at onset and diagnosis in the series of 676 patients with ulcerative colitis 
Table 2 Ulcerative colitis: distribution by sex, extent of disease, and operative procedure

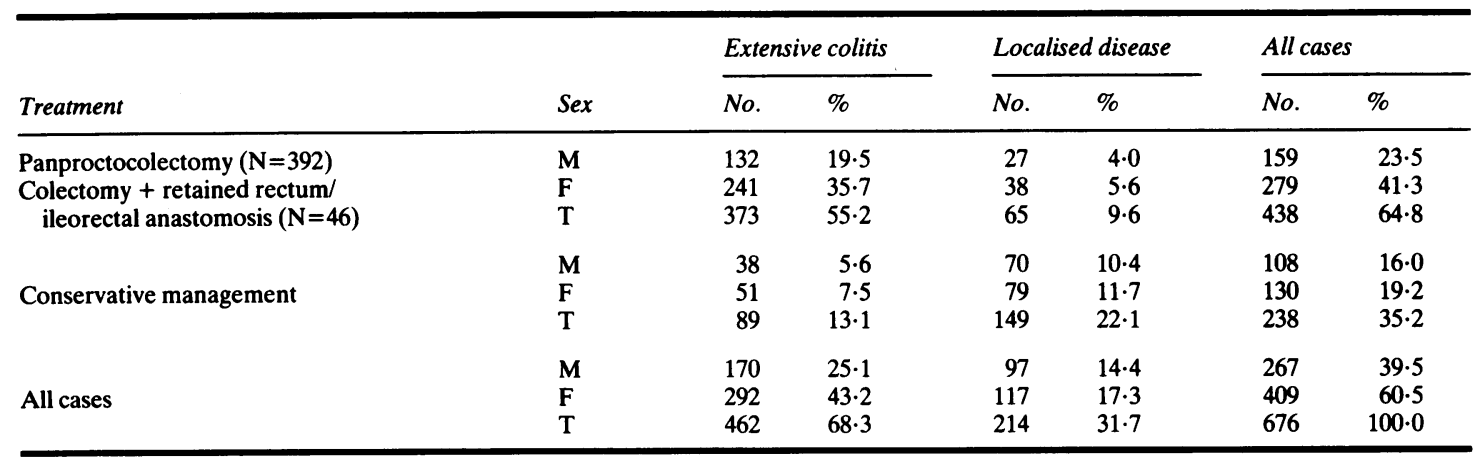

Males: females $=1: 1 \cdot 53$

order to correct for excision of the large intestine or rectum, the patient-years at risk accruing after colectomy or panproctocolectomy were subtracted from the total patient years at risk to give 'colorectal-years' at risk.

\section{Expected numbers of cancers}

Incidence rates for cancer at individual anatomical sites were computed from data held at the Birmingham and West Midlands Regional Cancer Registry for the years 1960-62, the mid-point of the study. The age-, sex-, and site-specific incidence rates were applied to the corresponding patient-years at risk to compute the number of cancers that might be expected to occur in the series during the period of review.

The expected numbers of colorectal cancers were computed both for total and for 'colorectal years' at risk. Colorectal cancers observed in the series were divided by mode of diagnosis into three clinical groups. These groups reflect possible areas of bias in the selection of patients which could affect the estimates of cancer risk.

1 'Referred' Symptoms of cancer in this group were instrumental in initiating the first referral of the patient to the unit, and, therefore, represent selection for cancer.

2 'Non-symptomatic' The cancers included in this group were identified as incidental findings among patients undergoing panproctocolectomy for symptomatic colitis shortly after referral to the unit, having been diagnosed elsewhere. The presence of the cancer was not considered to have initiated referral.

3 'Interval' These cancers were identified at review or at operation at least one year after the date first seen at the Unit.

Cancers were allocated to these groups on review of the clinical material before the tabulations of expected numbers were drawn up and none was changed subsequently.

The pattern of cumulative relative risk (sum of the observed/sum of the expected numbers) of colorectal cancer over time was first determined by using all observed cancers with expected numbers uncorrected for operation. The analysis was repeated with the expected numbers corrected for operation. Three further analyses were carried out to show the effect that each of the three clinical groups of observed cancers had on the level of risk and the pattern of risk over time, using as observed numbers:

A 'Referred' + 'non-symptomatic' + 'interval' cancers

B 'Non-symptomatic' + 'interval' cancers

C 'Interval' cancers only.

In each case the expected numbers were corrected for operation.

A conventional actuarial analysis was performed using 'non-symptomatic' + 'interval' cancers with 'colorectal' years at risk.

The level and pattern risk of colorectal cancer over time was also examined in relation to age at diagnosis of ulcerative colitis for three age-ranges (0-29 years, 30-44 years, and $45+$ years) using 'non-symptomatic' and 'interval' cancers with the expected numbers corrected for operation.

\section{Observed numbers of cancers}

Patients who developed cancer during the period of review were identified from the clinical records, by searches of the Birmingham Cancer Registry records, and from death certificates. Patients referred with a diagnosis of cancer were categorised separately if it was considered that the cancer was instrumental in initiating the first referral. 


\section{Interpretation}

The statistical significance between the observed and expected numbers of cancer was determined using the Poisson distribution. The force of the association between cancer and ulcerative colitis has been measured in terms of a Standardised Morbidity Ratio (SMR) where

$$
\text { SMR }=\frac{\text { Observed rate }}{\text { Expected rate }}
$$

which, in the context of patient-years at risk as a common denominator, can be expressed as observed number/expected number. The more familiar term of 'relative risk' has been used in the text.

The results are presented by the main anatomical divisions, with expected numbers for colon and rectum corrected for resection.

\section{Results}

A highly significant excess of cancers overall was observed in the series (Table 3 ). The excess was due entirely to cancers diagnosed within the digestive system, for which the relative risk was of the same order for both men and women. In women, no other system or site was significantly over- or underrepresented in the observed numbers. In men, the excess overall was significant at only the $5 \%$ level because of a small deficit (of marginal statistical significance) of cancers of the respiratory system.

A more detailed analysis of cancers of the digestive system is shown in Table 4. The excess of cancers in the colon and rectum was highly significant both for men and women, and the level of risk for the colon was the same as that for the rectum. A highly significant excess of cancers was found in liver and gall bladder. The remainder of the tract showed a small deficit which was of marginal significance and was due mainly to the absence of stomach cancers in this series. However, when those sites which showed a significant excess of cancers had been accounted for - namely, colon, rectum, liver and gall bladder - the expected number for all other sites (29.36) was close to the number observed (27).

Thirty-five colorectal cancers were observed in the series during the review period comprising 12 referred cancers, 10 non-symptomatic, and 13 interval cancers. The clinical details of the cancers including site, Dukes's classification, and outcome are summarised in Table 5 .

When no correction was made to the expected numbers, the risk of colorectal cancer relative to the general population decreased with time from the diagnosis of ulcerative colitis from $15 \cdot 5$-fold at five years to $9 \cdot 3$-fold at the end of the review period (Fig. 2, $A^{1}$ ). Correction for operation resulted in a
Table 3 Ulcerative colitis: cancer morbidity by anatomical system $\dagger$

\begin{tabular}{|c|c|c|c|c|c|}
\hline Site & Sex & $E$ & $O$ & $O / E$ & $p$ \\
\hline All sites & $\begin{array}{l}\mathbf{M} \\
\mathrm{F} \\
\mathrm{T}\end{array}$ & $\begin{array}{l}11.77 \\
19.99 \\
31.76\end{array}$ & $\begin{array}{l}19 \\
38 \\
57\end{array}$ & $\begin{array}{l}1.6 \\
1.9 \\
1.8\end{array}$ & $\begin{array}{l}* \\
* * * \\
* * *\end{array}$ \\
\hline Buccal cavity/throat & $\begin{array}{l}M \\
F \\
T\end{array}$ & $\begin{array}{l}0.40 \\
0 \cdot 42 \\
0 \cdot 82\end{array}$ & $\begin{array}{l}0 \\
0 \\
0\end{array}$ & $\begin{array}{l}- \\
-\end{array}$ & $\frac{-}{-}$ \\
\hline Digestive system & $\begin{array}{l}\mathbf{M} \\
\mathrm{F} \\
\mathrm{T}\end{array}$ & $\begin{array}{l}3 \cdot 16 \\
4 \cdot 19 \\
7 \cdot 35\end{array}$ & $\begin{array}{l}14 \\
17 \\
31\end{array}$ & $\begin{array}{l}4 \cdot 4 \\
4 \cdot 1 \\
4 \cdot 2\end{array}$ & $\begin{array}{l}* * * \\
* * * \\
* * *\end{array}$ \\
\hline Respiratory system & $\begin{array}{l}\mathrm{M} \\
\mathrm{F} \\
\mathrm{T}\end{array}$ & $\begin{array}{l}4.47 \\
0.96 \\
5.43\end{array}$ & $\begin{array}{l}0 \\
1 \\
1\end{array}$ & $\begin{array}{l}- \\
1 \cdot 0 \\
0 \cdot 2\end{array}$ & $\frac{\left({ }^{*}\right)}{\left({ }^{*}\right)}$ \\
\hline $\begin{array}{l}\text { Breast/reproductive } \\
\text { system }\end{array}$ & $\begin{array}{l}\mathrm{M} \\
\mathrm{F} \\
\mathrm{T}\end{array}$ & $\begin{array}{r}0.73 \\
10.29 \\
11.02\end{array}$ & $\begin{array}{r}0 \\
11 \\
11\end{array}$ & $\begin{array}{l}\overline{1 \cdot 1} \\
1 \cdot 0\end{array}$ & - \\
\hline Urinary system & $\begin{array}{l}M \\
F \\
T\end{array}$ & $\begin{array}{l}0.69 \\
0 \cdot 41 \\
1 \cdot 10\end{array}$ & $\begin{array}{l}1 \\
0 \\
1\end{array}$ & $\frac{1.4}{0.9}$ & - \\
\hline $\begin{array}{l}\text { Reticuloendothelial } \\
\text { system }\end{array}$ & $\begin{array}{l}M \\
F \\
T\end{array}$ & $\begin{array}{l}0.63 \\
0.85 \\
1.48\end{array}$ & $\begin{array}{l}1 \\
2 \\
3\end{array}$ & $\begin{array}{l}1 \cdot 6 \\
2 \cdot 4 \\
2 \cdot 0\end{array}$ & $\underline{-}$ \\
\hline Skin & $\begin{array}{l}M \\
F \\
T\end{array}$ & $\begin{array}{l}1.22 \\
1.81 \\
3.03\end{array}$ & $\begin{array}{l}3 \\
1 \\
4\end{array}$ & $\begin{array}{l}2.5 \\
0.6 \\
1.3\end{array}$ & Z \\
\hline Unknown primary & $\begin{array}{l}M \\
F \\
T\end{array}$ & $\begin{array}{l}0.33 \\
0.62 \\
0.95\end{array}$ & $\begin{array}{l}1 \\
2 \\
3\end{array}$ & $\begin{array}{l}3 \cdot 0 \\
3 \cdot 2 \\
3 \cdot 2\end{array}$ & Z \\
\hline Remainder & $\begin{array}{l}M \\
F \\
T\end{array}$ & $\begin{array}{l}0.54 \\
0.86 \\
1.40\end{array}$ & $\begin{array}{l}0 \\
3 \\
3\end{array}$ & $\begin{array}{l}- \\
3 \cdot 5 \\
2 \cdot 1\end{array}$ & - \\
\hline
\end{tabular}

† Expected number of cancers corrected for operation, observed numbers excluding 12 patients referred with colorectal cancer at first attendance.

$E=$ Expected number of cancers. $O=$ Observed number of cancers.

${ }^{*} \mathrm{p}<0.05 .{ }^{* *} \mathrm{p}<0 \cdot 01 .{ }^{* * *} \mathrm{p}<0 \cdot 001$. ( ) Deficit.

17-fold constant cumulative relative risk in the review period from five years after the diagnosis of ulcerative colitis had been established (Fig. 2A).

The effects of the previously defined cancer groups on the estimates of cancer risk are illustrated in Fig. 3. The constant 17 -fold risk, which was obtained when all cancers (referred, non-symptomatic, and interval) were included (Fig. 3A), was reduced to an 11-fold risk when 'referred' cancers were excluded from the analysis (Fig. 3B). The relative risk still remained constant over time.

When the 'interval' cancers alone were considered, the pattern of risk changed. There was an 
Table 4 Ulcerative colitis: cancer morbidity with particular reference to colon, rectum, liver, and gall bladder $\dagger$

\begin{tabular}{|c|c|c|c|c|c|}
\hline Site & Sex & $E$ & $O$ & $O / E$ & $p$ \\
\hline All sites & $\begin{array}{l}\mathbf{M} \\
\mathbf{F} \\
\mathrm{T}\end{array}$ & $\begin{array}{l}11 \cdot 77 \\
19 \cdot 99 \\
31 \cdot 76\end{array}$ & $\begin{array}{l}19 \\
38 \\
57\end{array}$ & $\begin{array}{l}1.6 \\
1.9 \\
1.8\end{array}$ & $\begin{array}{l}* \\
* * * \\
* * *\end{array}$ \\
\hline Digestive system & $\begin{array}{l}\mathbf{M} \\
\mathbf{F} \\
\mathrm{T}\end{array}$ & $\begin{array}{l}3 \cdot 16 \\
4 \cdot 19 \\
7 \cdot 35\end{array}$ & $\begin{array}{l}14 \\
17 \\
31\end{array}$ & $\begin{array}{l}4 \cdot 4 \\
4 \cdot 1 \\
4 \cdot 2\end{array}$ & $\begin{array}{l}* * * \\
* * * \\
* * *\end{array}$ \\
\hline Colon & $\begin{array}{l}\mathbf{M} \\
\mathbf{F} \\
\mathbf{T}\end{array}$ & $\begin{array}{l}0.29 \\
0.89 \\
1 \cdot 18\end{array}$ & $\begin{array}{r}5 \\
8 \\
13\end{array}$ & $\begin{array}{r}17 \cdot 2 \\
9 \cdot 0 \\
11.0\end{array}$ & $\begin{array}{l}* * * \\
* * * \\
* * *\end{array}$ \\
\hline Rectum & $\begin{array}{l}\mathrm{M} \\
\mathrm{F} \\
\mathrm{T}\end{array}$ & $\begin{array}{l}0.32 \\
0 \cdot 58 \\
0 \cdot 90\end{array}$ & $\begin{array}{r}3 \\
7 \\
10\end{array}$ & $\begin{array}{r}9 \cdot 4 \\
12 \cdot 1 \\
11 \cdot 1\end{array}$ & $\begin{array}{l}* * \\
* * * \\
* * *\end{array}$ \\
\hline Liver, gall bladder & $\begin{array}{l}M \\
F \\
T\end{array}$ & $\begin{array}{l}0 \cdot 11 \\
0 \cdot 21 \\
0 \cdot 32\end{array}$ & $\begin{array}{l}5 \\
2 \\
7\end{array}$ & $\begin{array}{r}45 \cdot 5 \\
9 \cdot 5 \\
21 \cdot 9\end{array}$ & $\begin{array}{l}* * * \\
* \\
* * *\end{array}$ \\
\hline $\begin{array}{l}\text { Remainder of } \\
\text { digestive system }\end{array}$ & $\begin{array}{l}M \\
F \\
T\end{array}$ & $\begin{array}{l}2 \cdot 44 \\
2 \cdot 51 \\
4.95\end{array}$ & $\begin{array}{l}1 \\
0 \\
1\end{array}$ & $\frac{0 \cdot 4}{0 \cdot 2}$ & $\overline{-}$ \\
\hline $\begin{array}{l}\text { All other sites excluding } \\
\text { colon, rectum, } \\
\text { liver, gall bladder }\end{array}$ & $\begin{array}{l}M \\
F \\
T\end{array}$ & $\begin{array}{l}11 \cdot 05 \\
18 \cdot 31 \\
29 \cdot 36\end{array}$ & $\begin{array}{r}6 \\
21 \\
27\end{array}$ & $\begin{array}{l}0.5 \\
1 \cdot 1 \\
0.9\end{array}$ & $\begin{array}{l}- \\
-\end{array}$ \\
\hline
\end{tabular}

$\dagger$ Expected number of cancers corrected for operation, observed numbers excluding 12 patients referred with colorectal cancer at first attendance.

$E=$ Expected number of cancers. $O=$ Observed number of cancers.

${ }^{*} p<0.05 .{ }^{* *} p<0 \cdot 01 .{ }^{* * *} p<0.001$. ( ) Deficit.

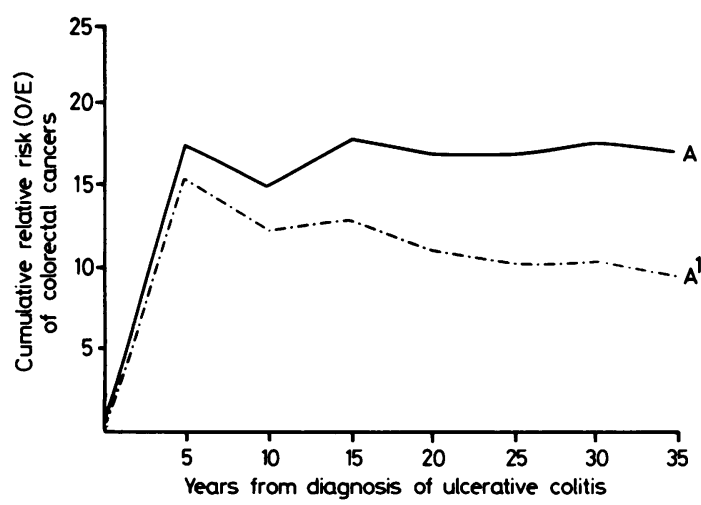

Fig. 2 Cumulative relative risk of colorectal cancers: $A^{\top}$-Observed number $=$ all colorectal cancers (35); expected number unadjusted for operation (all age groups). $A-O b s e r v e d$ number $=$ all colorectal cancers; expected number adjusted for operation (all age groups).

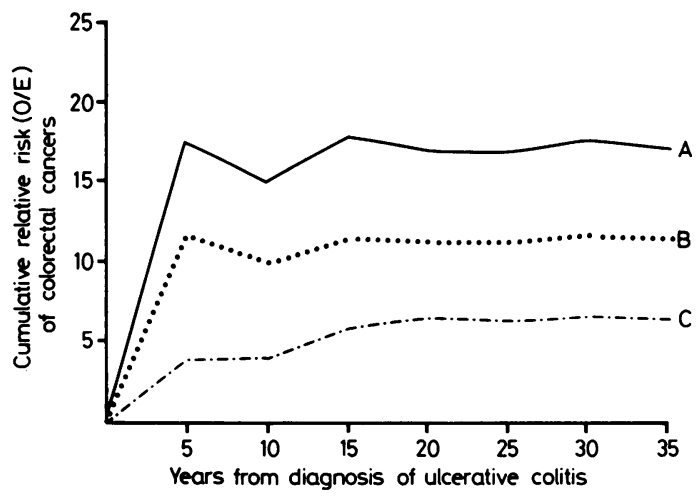

Fig. 3 Cumulative relative risk of colorectal cancers: $A$ - Observed number = all colorectal cancers; expected number adjusted for operation (all age groups). B Observed number = 'non-symptomatic' and 'interval' cancers (23); expected number adjusted for operation (all age groups). C - Observed number = 'interval cancers' (13); expected number adjusted for operation.

increasing relative risk of developing cancer up to 15 years from the diagnosis of ulcerative colitis with a constant six-fold risk thereafter (Fig. 3C).

These results emphasise the disparity between estimates of risk that can arise as a result of arbitrary selection of data.

It is generally, although not invariably,,$^{16}$ accepted that 'referred' cancers should be excluded from the analyses, as they are selectively drawn by their symptoms of cancer from an unknown group of patients with ulcerative colitis in the general population. In the remaining analyses, therefore, these referred cancers were excluded and 'nonsymptomatic' and 'interval' cancers only were considered.

The actuarial analysis showed that the probability of developing colorectal cancers in the series increased exponentially with time (Fig. 4). Despite the size of the initial series the $95 \%$ confidence limits for the estimation became increasingly wide with time. The probability at 25 years was $8 \%(3 \cdot 5-13 \%)$ and $20 \%(4 \cdot 5-36 \%)$ at 30 years but the figure at 30 years is based on the addition of only one further cancer. As the expected cancer risk increased at a similar rate the cumulative relative risk $(\mathrm{O} / \mathrm{E})$ over time remained constant and at the same level as shown in Fig. 3B.

The relative risk of developing colorectal cancer was 38-fold overall in patients aged between 0-29 years when their ulcerative colitis was diagnosed and it fell as the age at diagnosis increased (Table 6, 
Table 5 Clinical data: cancer morbidity: $(A)$ colorectal cancer

\begin{tabular}{|c|c|c|c|c|c|c|c|}
\hline No. & Sex & $\begin{array}{l}\text { Age at onset } \\
\text { of symptoms } \\
\text { of ulcerative } \\
\text { colitis }(y r)\end{array}$ & $\begin{array}{l}\text { Age at } \\
\text { diagnosis of } \\
\text { cancer }(y r)\end{array}$ & $\begin{array}{l}\text { Interval from onset of } \\
\text { symptoms of ulcerative } \\
\text { colitis to diagnosis } \\
\text { of cancer (yr) }\end{array}$ & Site of cancer & $\begin{array}{l}\text { Age at death or } \\
\text { length of survival } \\
\text { from diagnosis of } \\
\text { cancer }(y r) \S\end{array}$ & $\begin{array}{l}\text { Dukes's } \\
\text { classification }\end{array}$ \\
\hline 428 & $\mathbf{F}$ & 42 & 54 & 12 & Sigmoid colon & 54 & $\mathrm{D}$ \\
\hline 685 & $\mathbf{F}$ & 29 & 50 & 21 & Multiple colon & 52 & B \\
\hline 156 & $\mathbf{F}$ & 10 & 43 & 33 & Transverse colon & Survival 14 yr & A \\
\hline 573 & $\mathbf{F}$ & 16 & 33 & 17 & Descending colon & Survival $18 \mathrm{yr}$ & $\mathrm{A}^{*}$ \\
\hline 276 & $\mathbf{F}$ & 39 & 54 & 15 & Transverse colon & 55 & $\mathrm{~B}^{*}$ \\
\hline 396 & $\mathbf{F}$ & 21 & 50 & 29 & Transverse colon & 50 & D \\
\hline 313 & $\mathbf{F}$ & 25 & 35 & 10 & Transverse colon & 35 & D \\
\hline 310 & $\mathbf{F}$ & 37 & 49 & 12 & Descending colon & 49 & $\mathrm{C}^{*}$ \\
\hline 218 & $\mathbf{F}$ & 42 & 54 & 12 & Multiple colon & Survival $12 \mathrm{yr}$ & $1 C+6 A \ddagger$ \\
\hline 369 & $\mathbf{F}$ & 21 & 39 & 18 & Sigmoid colon & Survival 13 yr & $\mathrm{B}^{*}$ \\
\hline 282 & $\mathrm{~F}$ & 24 & 49 & 25 & Transverse colon & 49 & B \\
\hline 636 & $\mathbf{F}$ & 34 & 45 & 11 & Ascending colon & Survival $25 \mathrm{yr}$ & A \\
\hline 403 & $\mathbf{F}$ & 22 & 44 & 22 & Multiple sigmoid colon & 45 & $1 \mathrm{C}+1 \mathrm{~A} \ddagger$ \\
\hline 801 & $\mathbf{F}$ & 7 & 32 & 25 & Rectum & 34 & $-\dagger$ \\
\hline 529 & $\mathbf{F}$ & 34 & 55 & 21 & Rectum & 56 & $\mathrm{C}^{*}$ \\
\hline 292 & $\mathbf{F}$ & 25 & 74 & 49 & Rectum & 78 & A \\
\hline 542 & $\mathrm{~F}$ & 25 & 41 & 16 & Rectum & 50 & $\mathrm{D}$ \\
\hline 506 & $\mathbf{F}$ & 28 & 53 & 25 & Rectosigmoid & 53 & D \\
\hline 559 & $\mathbf{F}$ & 37 & 52 & 15 & Rectum & 52 & D \\
\hline 622 & $\mathrm{~F}$ & 31 & 44 & 12 & Rectum & Survival $23 \mathrm{yr}$ & + \\
\hline 624 & $\mathrm{~F}$ & 31 & 55 & 24 & Rectum & 56 & $\mathrm{C}^{*}$ \\
\hline 406 & $\mathbf{F}$ & 27 & 57 & 30 & Rectosigmoid & Survival $20 \mathrm{yr}$ & $\mathrm{C}$ \\
\hline 684 & $\mathrm{~F}$ & 29 & 43 & 14 & Rectosigmoid & 43 & D \\
\hline 512 & $\mathbf{M}$ & 7 & 34 & 27 & Sigmoid & 35 & D \\
\hline 434 & $\mathbf{M}$ & 34 & 49 & 15 & Caecum & 52 & $\mathrm{C}$ \\
\hline 569 & $\mathbf{M}$ & 24 & 55 & 31 & Caecum & Survival 3 yr & + \\
\hline 575 & $\mathbf{M}$ & 24 & 39 & 14 & Sigmoid & 40 & B \\
\hline 180 & $\mathbf{M}$ & 14 & 40 & 16 & Hepatic flexure & Survival 9 yr & B \\
\hline 206 & $\mathbf{M}$ & 24 & 40 & 16 & Hepatic flexure & Survival 21 yr & $A^{*}$ \\
\hline 222 & $\mathbf{M}$ & 27 & 41 & 14 & Transverse colon & Survival $23 \mathrm{yr}$ & A \\
\hline 66 & M & 23 & 47 & 24 & Rectum & Survival $0.5 \mathrm{yr}$ & \\
\hline 606 & $\mathbf{M}$ & 24 & 46 & 22 & Rectum & 46 & $-\dagger$ \\
\hline 627 & $\mathbf{M}$ & 46 & 54 & 8 & Rectum & 54 & $\mathrm{C}$ \\
\hline 259 & $\mathbf{M}$ & 24 & 41 & 17 & Rectum & Survival 23 yr & -+ \\
\hline 686 & $\mathbf{M}$ & 35 & 52 & $\begin{array}{l}17 \\
\text { sigmoid-rectum }\end{array}$ & Multifocal & Survival $17 \mathrm{yr}$ & $\mathbf{A}$ \\
\hline
\end{tabular}

* Dukes's classification: assessment made from original histology report - slides of original histology not available for review.

+ Dukes's classification could not be established from available histology when reviewed.

$\ddagger$ Multiple colon cancers.

All cases of colorectal carcinoma had extensive colitis at diagnosis of carinoma

All deaths related to colorectal cancer except patient 310 (postoperative death) and patient 166 (cerebrovascular accident).

§ Survival to 31.12 .76 .

Fig. 5). There was a two-fold risk among patients diagnosed with ulcerative colitis after 45 years of age (Fig. 5) but this did not reach statistical significance (Table 6).

The cancers in the series were diagnosed at a relatively early age when compared with those expected in the general population (Fig. 6). The age-specific relative risk decreased with age even though a substantial number of person-years at risk $(1430.7$ at $60+$ years) was available for analysis. The risk of cancer in the colon and rectum when analysed separately was similar with an 11-fold risk (Table 7).

\section{Discussion}

A highly significant excess of cancers of the digestive system was found in the series, the increased risk being confined to cancers of the colon, rectum, and gall bladder. The fact that the numbers of cancers observed at other sites were close to the numbers expected suggests that there was no undue selection for cancers of the digestive tract in preference to other sites. The increased colorectal cancer risk in the series when compared with that in the general population is likely therefore to be real rather than due to selection factors operating in the series. 


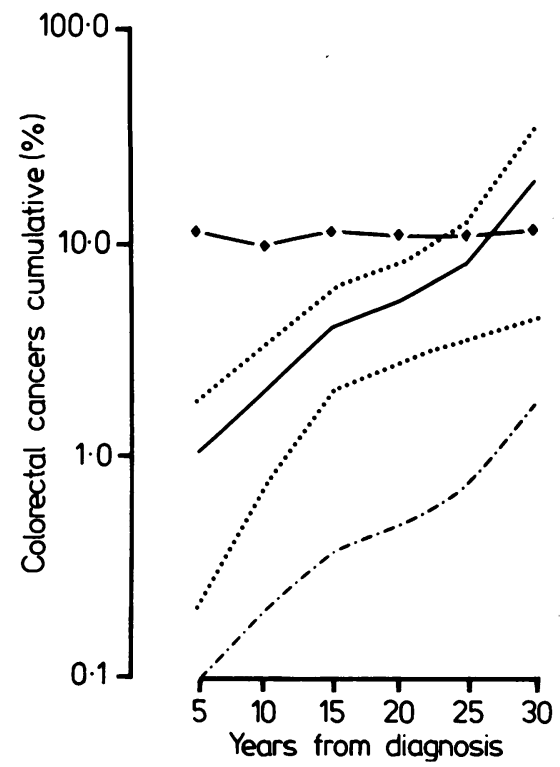

Fig. 4 Risk of colorectal cancers during review period. Observed cumulative risk (\%) of colorectal cancers adjusted for operation and based on 'non-symptomatic' and 'interval' cancers (-) with $95 \%$ confidence limited (..........). Expected cumulative risk (\%) $(\cdot-\cdot-\cdot)$. Cumulative relative risk (- $-\downarrow)$. Observed number $=$ 'nonsymptomatic' and 'interval' cancers, expected number adjusted for operation.

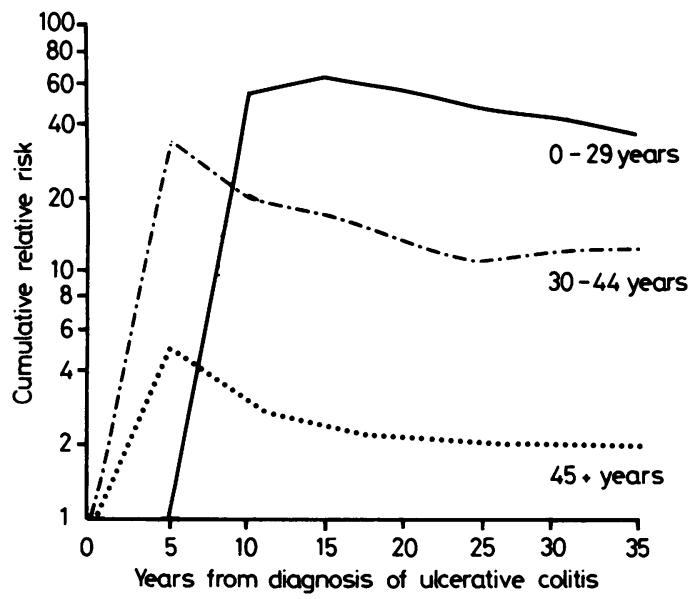

Fig. 5 Cumulative relative risk of colorectal cancers by age at diagnosis of ulcerative colitis; 0.29 years (-); 30-44 years $(\cdot-\cdot-\cdot) ; 45+$ years $(\ldots \ldots \ldots$.$) . Observed numbers$ $=$ 'non-symptomatic' and 'interval' cancers, expected number adjusted for operation.
Table 6 Colorectal cancers in relation to age at diagnosis of ulcerative colitis $\dagger$

\begin{tabular}{|c|c|c|c|c|c|c|c|}
\hline \multirow{2}{*}{$\begin{array}{l}\text { Age at } \\
\text { diagnosis } \\
(y r)\end{array}$} & \multicolumn{4}{|c|}{$\begin{array}{l}\text { Non-symptomatic + interval } \\
\text { cancers }\end{array}$} & \multicolumn{3}{|c|}{ Interval cancers } \\
\hline & $E$ & $O$ & $O / E$ & $p$ & $O$ & $O / E$ & $p$ \\
\hline $0-29$ & $0 \cdot 29$ & 11 & $37 \cdot 9$ & $* * *$ & 8 & $27 \cdot 6$ & *** \\
\hline $30-44$ & 0.81 & 10 & $12 \cdot 3$ & $* * *$ & 3 & 3.7 & ${ }^{*}$ \\
\hline $45+$ & 0.98 & 2 & $2 \cdot 0$ & - & 2 & $2 \cdot 0$ & - \\
\hline TOTAL & $2 \cdot 08$ & 23 & $11 \cdot 1$ & $* * *$ & 13 & $6 \cdot 3$ & $* * *$ \\
\hline \multicolumn{8}{|c|}{ 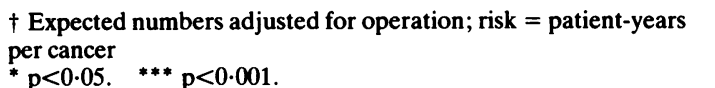 } \\
\hline
\end{tabular}

When patients referred with symptomatic cancer on their first visit ('referred' cancers) were excluded from the analysis (removing this obvious bias towards selection for cancer) and corrections made to the patient-years at risk for surgical resection an 11 -fold risk was found in the series (the 95\% confidence limits for this ratio are $7 \cdot 0-16 \cdot 7)$. A comparison of our results with other series analysed by comparable methods shows that the relative risk in our series is similar to that reported by Edwards and Truelove ${ }^{5}$ and also by MacDougall ${ }^{6}$ (Table 8 ). Gilat $e t a l^{7}$ report a much lower cancer risk from Tel

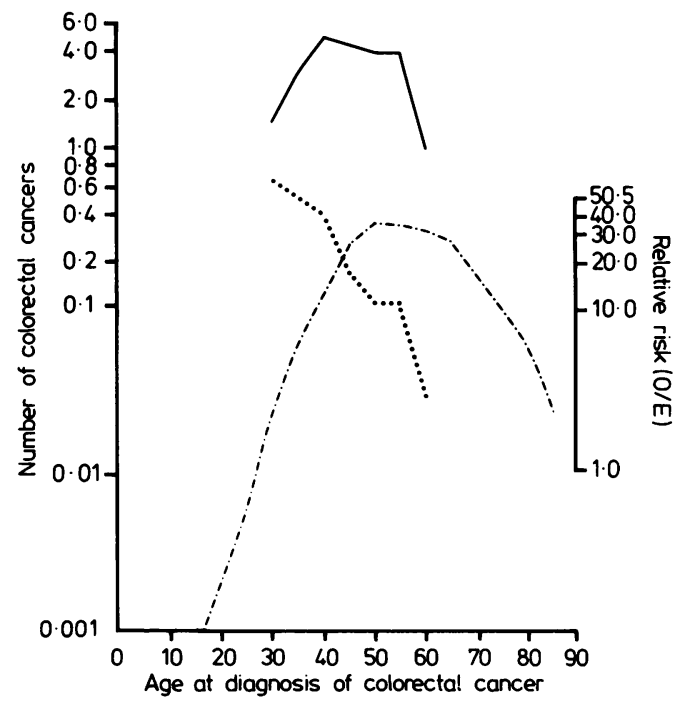

Fig. 6 Observed (—) and expected numbers $(\cdot-\cdot-\cdot)$ of colorectal cancers by age at diagnosis of cancer with corresponding relative risk: observed/expected number (........). Observed number = 'non-symptomatic' and 'interval' cancers, expected number adjusted for operation. 
Table 7 Colorectal and hepatobiliary cancers in patients with ulcerative colitis

\begin{tabular}{lrrrl}
\hline Site & $E$ & $O$ & $O / E$ & $p$ \\
\hline All sites & 31.76 & 57 & 1.8 & ${ }^{* * *}$ \\
Colon & 1.18 & 13 & 11.0 & ${ }^{* * *}$ \\
Rectum & 0.90 & 10 & 11.1 & ${ }^{* * *}$ \\
Liver, gall bladder & 0.32 & 7 & 21.9 & ${ }^{* * *}$ \\
Remainder & 29.36 & 27 & 0.9 & - \\
\hline
\end{tabular}

$E=$ expected number. $O=$ observed number.

${ }^{* * *} \mathrm{p}<0.001$.

Aviv (Table 8). A more conservative estimate of the risk in this series can be calculated by considering only those cancers diagnosed after one or more years of follow-up ('interval' cancers). This eliminates any possible bias in the series arising from early cancers identified unexpectedly ('nonsymptomatic' cancers) in patients referred to the unit specifically for early surgical treatment. When 'interval' cancers alone are considered there is a six-fold overall risk in the series.

The pattern of increased colorectal cancer risk over time in this series is of interest, as, whichever model is used, there is a constant increased risk with time 15 years after diagnosis rather than a rising risk with time as might have been expected (Fig. 3). This applies to all ages of onset of disease (Fig. 5). This constant risk is surprising, as a rising relative risk with time might be expected if inflammation were acting as an additional promotional factor for the development of cancer in the ulcerative colitis group when compared with the general population.

The cancer risk in the colon and rectum is similar if the two sites are analysed separately (Table 7). As the rectum is almost invariably involved from onset of disease a higher relative risk of rectal cancers might be expected if inflammation were implicated as a promotional factor.

Table 8 Relative risk of colorectal cancer in ulcerative colitis in previously reported unselected series

\begin{tabular}{|c|c|c|c|c|c|}
\hline \multirow[b]{2}{*}{ Study } & \multirow{2}{*}{$\begin{array}{l}\text { No. of } \\
\text { patients }\end{array}$} & \multirow{2}{*}{$\begin{array}{l}\text { Site of } \\
\text { cancer }\end{array}$} & \multicolumn{2}{|c|}{ Cancers } & \multirow[b]{2}{*}{$O / E$} \\
\hline & & & Expe & d Observed & \\
\hline \multicolumn{2}{|c|}{ Edwards and Truelove } & \multirow{4}{*}{$\begin{array}{l}\text { Colo- } \\
\text { rectal } \\
\text { Colo- } \\
\text { rectal }\end{array}$} & & & \\
\hline $1964^{5}$ Oxford & 624 & & $3 \cdot 0$ & 22 & $7 \cdot 3$ \\
\hline MacDougall & & & & & \\
\hline $1964^{6}$ London & 724 & & $1 \cdot 21$ & 15 & $12 \cdot 4$ \\
\hline $\begin{array}{l}\text { Gilat et al } \\
1074^{7} \text { Tel Aviv }\end{array}$ & & & & & \\
\hline $1974^{\prime}$ Tel Aviv & 504 & Colon & $\begin{array}{l}0.9 \\
1.18\end{array}$ & $\begin{array}{r}3 \\
13\end{array}$ & $\begin{array}{r}3 \cdot 3 \\
11 \cdot 0\end{array}$ \\
\hline Present series & 676 & $\left\{\begin{array}{l}\text { Colon } \\
\text { Rectum }\end{array}\right.$ & $\begin{array}{l}1 \cdot 18 \\
0.90\end{array}$ & $\begin{array}{l}13 \\
10\end{array}$ & $\begin{array}{l}11 \cdot 0 \\
11 \cdot 1\end{array}$ \\
\hline
\end{tabular}

In this series the age at onset of ulcerative colitis affects the colorectal cancer risk. The relative risk of developing colorectal cancer is significantly increased in patients whose ulcerative colitis is diagnosed before 30 years of age (Table 6), but not in those diagnosed over 45 years. Patients diagnosed between ages 30 and 44 years show an intermediate level of risk. The pattern of risk over time is similar in each age group.

The constant relative risk over time and the marked effect of age at onset on the level of the colorectal cancer risk may be clues to the aetiology of colorectal cancer in ulcerative colitis but the relationship is as yet unexplained.

\section{References}

1 Slaney G, Brooke BN. Cancer in ulcerative colitis. Lancet 1959; 2: 694-8.

2 Lennard-Jones JE, Morson $\mathrm{BC}$, Ritchie JK, et al. Cancer in colitis: assessment of the individual risk by clinical and histological criteria. Gastroenterology 1977; 73: $1280-9$.

3 Whelan G. Cancer in ulcerative colitis: why are results in the literature so varied? Clin Gastroenterol 1980; 9: 469-76.

4 Goldgraber MB, Humphreys EM, Kirsner JB, et al. Carcinoma and ulcerative colitis, a clinical-pathological study. Gastroenterology 1958; 34: 840-6.

5 Edwards FC, Truelove SC. Course and prognosis of ulcerative colitis. Part IV. Cancer of the colon. Gut 1964; 5: 15-22.

6 MacDougall IP. The cancer risk in ulcerative colitis. Lancet 1964; 2: 655-8.

7 Gilat T, Zemishlany Z, Ribak J, et al. Ulcerative colitis in a Jewish population of Tel-Aviv Yafo. Gastroenterology 1974; 67: 933-8.

8 Kewenter J, Ahlam H, Hulton L. Cancer risk in extensive colitis. Ann Surg 1978; 188: 824-8.

9 Ritchie JK, Allan RN, Macartney J, et al. Biliary tract carcinoma associated with ulcerative colitis. $Q \mathrm{~J}$ Med 1974; 170: 263-79.

10 Akwari OE, Heerden JA, Foulk WT et al. Cancer of the bile ducts associated with ulcerative colitis. Ann Surg 1975: 181: 303-9.

11 Sackett DL, Whelan G. Cancer risk in ulcerative colitis. Scientific requirements for the study of prognosis. Gastroenterology 1980; 78: 1623-35.

12 Daly DW. The outcome of surgery for ulcerative colitis. Ann R Coll Surg Engl 1968; 42: 38-57.

13 Nefzger MD, Acheson ED. Ulcerative colitis in the United States army. Gut 1963; 4: 183-92.

14 Watts JMcK, DeDombal FT, Watkinson G et al. Early course of ulterative colitis. Gut 1966; 7: 16-31.

15 Bonnevie $\mathrm{O}$, Binder $\mathrm{V}$, Anthonisen $\mathrm{P}$ et al. The prognosis of ulcerative colitis. Scand J Gastroenterol 1974; 9: 81-91.

16 Greenstein AJ, Sachar DB, Smith H et al. Cancer in Universal and left-sided ulcerative colitis: factors determining risk. Gastroenterology 1979; 77: 290-4. 